\title{
Detection of Aqueous Phase Chemical Warfare Agent Degradation Products by Negative Mode Ion Mobility Time-of-Flight Mass Spectrometry [IM(tof)MS]
}

\author{
Wes E. Steiner, and Charles S. Harden \\ SAIC/Geo-Centers, Edgewood Chemical Biological Center Operations, Aberdeen Proving Ground, Maryland, \\ USA
}

Feng Hong, Steve J. Klopsch, and Herbert H. Hill, Jr.

Department of Chemistry, Washington State University, Pullman, Washington, USA

\author{
Vincent M. McHugh \\ United States Army Edgewood Chemical Biological Center, Aberdeen Proving Ground, Maryland, USA
}

The use of negative ion monitoring mode with an atmospheric pressure ion mobility orthogonal reflector time-of-flight mass spectrometer [IM(tof)MS] to detect chemical warfare agent (CWA) degradation products from aqueous phase samples has been determined. Aqueous phase sampling used a traditional electrospray ionization (ESI) source for sample introduction and ionization. Certified reference materials (CRM) of CWA degradation products for the detection of Schedule 1,2, or 3 toxic chemicals or their precursors as defined by the chemical warfare convention (CWC) treaty verification were used in this study. A mixture of six G-series nerve related CWA degradation products (EMPA, IMPA, EHEP, IHEP, CHMPA, and PMPA) and their related collision induced dissociation (CID) fragment ions (MPA and EPA) were found in each case to be clearly resolved and detected using the IM(tof)MS instrument in negative ion monitoring mode. Corresponding ions, masses, drift times, $K_{o}$ values, and signal intensities for each of the CWA degradation products are reported. (J Am Soc Mass Spectrom 2006, 17, 241-245) (C 2006 American Society for Mass Spectrometry

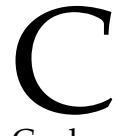
hemical warfare agents by convention are classified as lethal nerve, vesicant, blood, or pulmonary agents. Nerve agents, G-series (Sarin (GB), Cyclosarin (GF), Soman (GD), Tabun (GA), and V-series (VE, VG, VM, VX), all disrupt neurological regulation within biological systems through the inhibition of the enzyme acetylcholine esterase [1]. Vesicant agents (also known as bifunction alkylating agents) sulfur mustards (H, HD, HS), lewisite (L), nitrogen mustard gas (HN), and phosgene-oxime $(\mathrm{CX})$ are the agents typically responsible for detrimental reactions with deoxyribonucleic acid (DNA) and intracellular glutathione (GSH) [2]. Blood born agents, such as prussic acid (AC) or cyanogen chloride $(\mathrm{CK})$, prevent tissue utilization of oxygen by inhibition of the enzyme cytochrome oxidase [3]. Pulmonary agents, chlorine gas (C), chloropicrin (PS), diphosgene (DP), and phosgene $(C G$,$) all react$

Published online January 18, 2006

Address reprint requests to Dr. H. H. Hill, Jr., Department of Chemistry, Washington State University, Pullman, WA 99164, USA. E-mail: hhhill@wsu.edu with water to form hydrochloric acid and carbon monoxide to cause pulmonary edema [4]. Environment neutralization of these CWA typically involves the degradation of the parent compounds to yield various hydrolysis products [5-7]. The G-series nerve agents, which include GB, GF, GD, and GA, rapidly hydrolyze to form various alkyl phosphonic acids [8], whereas V-series nerve agents VE, VG, VM, and VX degrade to not only form alkyl phosphonic acids but phosphonothioic acids and various alkyl amino ethanol compounds [9]. The common sulfur and arsenic containing vesicants $H, H D, H S$, and L typically degrade to produce various sulfides, thiodiglycols, sulfones, and vinyl arsonous products, respectively [10]. Blood-born agents such as AC initially hydrolyze to formamide, and subsequently to ammonium formate, while CK readily hydrolyzes to hydrogen chloride and unstable cyanic acid. The cyanic acid further decomposes to carbon dioxide and ammonia [11]. Lastly, the pulmonary agents C, PS, DP, and CG as mentioned above hydrolyze into hydrochloric acid, hydrochlorous acid, carbon monoxide, and carbon dioxide [12]. 
In general, CWA hydrolysis and degradation products have been found to exhibit a higher degree of stability and persistence in the environment than their corresponding parent agents [5]. Direct detection of these CWA degradation products has provided a convenient and indirect detection method for the presence or past presence of CWA. The degradation products of CWA are typically polar and nonvolatile in character, readily dissolving in aqueous environments. A host of stand alone analytical techniques in an assortment of forms [7, 13-19] have been employed for the analysis of these CWA degradation products with varying degrees of success. More recently; however, the development of an atmospheric pressure ion mobility spectrometer (AP-IMS) interfaced to a orthogonal reflector time-offlight mass spectrometer (TOFMS) has demonstrated the capability through a variety of sample introduction and ionization modes to rapidly ( $<1 \mathrm{~min})$ and sensitively ( $<100 \mathrm{ppb}$ by weight for most compounds tested) detect, identify, and quantify aqueous vapor and aerosol phase CWA degradation products, respectively [2022]. More importantly, with the prior development of the AP-IMS [23] with resolving powers similar to that of typical capillary gas chromatography and better than that of typical HPLC separations has facilitated the AP-IMS-TOFMS [simply referred to here as IM(tof)MS] the option to eliminate traditional chromatographic separations altogether and rely solely upon the rapid separation capabilities of the high-resolution AP-IMS before mass spectrometric analysis via the TOFMS. Although rapid detection of aqueous vapor and aerosol phase CWA degradation products have been demonstrated with IM(tof)MS technology in the positive ion monitoring mode, negative ion monitoring mode using IM(tof)MS has not been previously explored. It is, however, interesting to note that negative ion monitoring mode detection applications utilizing atmospheric pressure field asymmetric ion mobility mass spectrometry (FAIMS-MS) have been investigated, but not for compounds involving CWA degradation product research. Likewise, CWA degradation products have been studied using FAIMS but not in combination with MS [24]. Therefore, this paper seeks to explore the feasibility of using IM(tof)MS technology for the detection of CWA degradation products in negative ion monitoring mode. This improvement in IM(tof)MS development greatly expands the capacity of IM(tof)MS technology to significantly decrease the potential for false positive responses when screening for CWA.

\section{Experimental}

\section{Chemicals and Solvents}

The six G-series nerve related CWA degradation products (ethyl methyl phosphonic acid (EMPA), isopropyl methyl phosphonic acid (IMPA), ethyl hydrogen ethyl phosphonate (EHEP), isopropyl hydrogen ethyl phosphonate (IHEP), cyclohexyl methyl phosphonic acid (CHMPA), and pinacolyl methyl phosphonic acid (PMPA) used in this study were obtained from Cerilliant (Round Rock, TX) as $1 \mu \mathrm{g} / \mathrm{mL}$ (1000 ppm) certified reference materials (CRM) in methanol. These CRMs are used as analytical standard solutions for the detection of Schedule 1, 2, or 3 toxic chemicals or their precursors as stated in the CWC verification and related analysis annex [25]. Stock solutions for these CWA simulants/degradation products were prepared in ESI solvent (90.0\% methanol, $10.0 \%$ water) at concentrations of 100 $\mu \mathrm{g} / \mathrm{mL}$ (100 ppm). Further dilutions of these stock solutions with ESI solvent ranged from 0.01 to $100 \mu \mathrm{g} / \mathrm{mL}$ (10 ppb to $100 \mathrm{ppm})$, depending upon the experiment. The HPLC grade ESI solvents (methanol, water) were purchased from J. T. Baker (Phillipsburgh, NJ).

\section{Instrumentation}

The fundamental components (ESI source, AP-IMS drift tube, pressure interface, TOFMS analyzer, and data acquisition system) of IM(tof)MS technology as used in this study were constructed over a period of time in collaboration with Washington State University and Ionwerks Incorporated, where only the positive mode of operation have been previously described in detail $[20-23,26]$. Thus, in light of previous work, only a brief outline of the experimental sequence in negative ion monitoring mode of operation is provided. A continuous flow $(1.0 \mu \mathrm{l} / \mathrm{min})$ of solvent was electrosprayed in the negative ion monitoring mode with a needle voltage drop of $-4.1 \mathrm{KV}$ with respect to the target screen of the APIMS. The APIMS was separated into two regions a desolvation $(8.0 \mathrm{~cm}$ long $)$ and a drift $(18.0 \mathrm{~cm}$ long) that were maintained at a temperature of $225^{\circ} \mathrm{C}$. Desolvated negatively charged ions from the electrospray process drifted through the APIMS tube under a weak uniform electric field $(-430 \mathrm{~V} / \mathrm{cm})$, which facilitated separation based upon differing analyte mobility constants. A counter current flow of preheated nitrogen drift gas was introduced at the end of the drift region at a rate of $1.0 \mathrm{~L} / \mathrm{min}$. Ions, upon exiting of the APIMS drift tube (689 torr), traversed a pressure interface (1.2 torr) where ions were transported through a series of lenses into the TOFMS $\left(4 \times 10^{-6}\right.$ torr $)$ for analysis.

Data acquisition for this experimental sequence consisted of a timing mechanism that was comprised of a real-time two-dimensional (2-D) matrix of simultaneous mobility drift and mass flight times. Ions were typically gated for $200 \mu$ s into the drift region at a frequency of 25.0 Hz. This allowed for a maximum of $40 \mathrm{~ms}$ for AP-IMS mobility data to be acquired. The TOFMS extraction frequency was set to $50.0 \mathrm{kHz}$, which provided a mass spectrum that consisted of ions with flight times up to 20 $\mu \mathrm{s}$. Therefore, within each $40 \mathrm{~ms}$ mobility time window there were effectively $2.00 \times 10^{3} \mathrm{TOF}$ extractions. The AP-IMS Bradbury-Nielsen ion gate, TOFMS extractor, and TOFMS time-to-digital converter were all triggered by a personal computer (PC) based timing controller. Synchronization of this electronic hardware was facilitated by the use of a dual Pentium III workstation running Ionwerks 


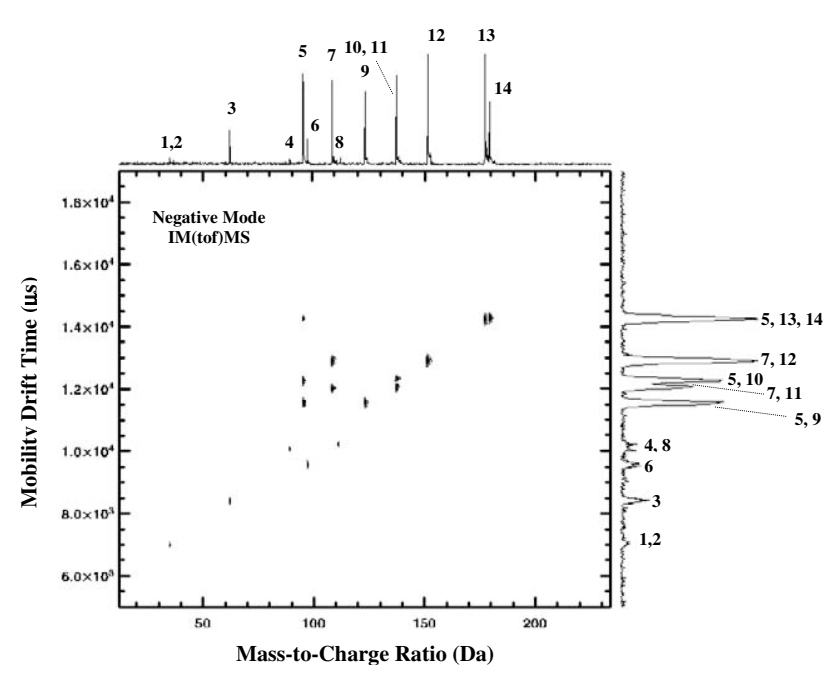

Figure 1. The IM(tof)MS of a $10 \mathrm{ppm}$ liquid phase mixture containing all six G-series CWA degradation products are shown in negative ion monitoring mode by both the 2-D mobility-mass spectrum and extracted mobility-mass spectra. Here the ESI background solvent ions were identified as 1 : Chloride $\left({ }^{35} \mathrm{Cl}\right)^{-}, 2$ : Chloride $\left({ }^{37} \mathrm{Cl}\right)^{-}, 3$ : Nitrate $\left(\mathrm{NO}_{3}\right)^{-}, 4$ : Water cluster $\left(\left[\mathrm{H}_{2} \mathrm{O}\right]_{4^{-}}\right.$ $\mathrm{OH})^{-}$, and the ions from the CWA degradation products were identified as 5: Fragmentation products methyl phosphonic acid (MPA-H) ${ }^{-}$, 6: Phosphate $\left(\mathrm{H}_{2} \mathrm{PO}_{4}\right)^{-}$, 7: Fragmentation products ethyl phosphonic acid $(\text { EPA-H })^{-}, 8$ : Phosphoric acid ester $\left(\mathrm{CH}_{3} \mathrm{HPO}_{4}\right)^{-}$, 9: Ethyl methyl phosphonic acid (EMPA-H) ${ }^{-}, 10$ : Isopropyl methyl phosphonic acid (IMPA-H) ${ }^{-}, 11$ : Ethyl hydrogen ethyl phosphonate (EHEP-H) ${ }^{-}, 12$ : Isopropyl hydrogen ethyl phosphonate (IHEP-H) ${ }^{-}$, 13: Cyclohexyl methyl phosphonic acid $(\text { CHMPA-H })^{-}$, 14: Pinacolyl methyl phosphonic acid (PMPA-H) ${ }^{-}$.

[27] three-dimensional (3-D) acquisition software. Experimental data acquisitions were run in triplicate for a typical run-time of $15.0 \mathrm{~min}$ per sample to provide clear ion statistics. This ensured that the effects of ionization efficiency and ion transmission were not a limiting factor when determining limits of detection. Once acquired, spectral compilations of data were then exported into Research Systems IDL virtual machine 6.0 software for processing [28].

\section{Results and Discussion}

A standard aqueous phase reference solution containing all six G-series CWA degradation products (EMPA, IMPA, EHEP, IHEP, CHMPA, and PMPA) were electrosprayed (9:1, methanol:water) at a rate of $1 \mu \mathrm{l} / \mathrm{min}$ into the IM(tof)MS instrument in negative ion monitoring mode. Figure 1 shows the 2-D IM(tof)MS separation of an acquisition $(15.0 \mathrm{~min})$ of a solution $(10 \mathrm{ppm})$ conducted at an AP-IMS temperature of $225^{\circ} \mathrm{C}$. The 2-D IM(tof)MS spectrum as seen in Figure 1 is also accompanied by a combination of both the extracted mobility (shown on the side of the 2-D spectrum) and mass (shown above the 2-D spectrum) spectra. Here, the ESI background solvent ions were identified as 1: chloride $\left({ }^{35} \mathrm{Cl}\right)^{-}$, 2: chloride $\left({ }^{37} \mathrm{Cl}\right)^{-}, 3$ : nitrate $\left(\mathrm{NO}_{3}\right)^{-}$, 4: water cluster $\left(\left(\mathrm{H}_{2} \mathrm{O}\right)_{4}-\mathrm{OH}\right)^{-}$, and the ions from the CWA degradation products were identified as 5 : fragmenta- tion products methyl phosphonic acid (MPA-H) ${ }^{-}, 6$ : phosphate $\left(\mathrm{H}_{2} \mathrm{PO}_{4}\right)^{-}$, 7: fragmentation products ethyl phosphonic acid (EPA-H $)^{-}$, 8: phosphoric acid ester $\left(\mathrm{CH}_{3} \mathrm{HPO}_{4}\right)^{-}$, 9: ethyl methyl phosphonic acid (EMPA$\mathrm{H})^{-}, 10$ : isopropyl methyl phosphonic acid (IMPA-H) ${ }^{-}$, 11: ethyl hydrogen ethyl phosphonate (EHEP-H) ${ }^{-}, 12$ : isopropyl hydrogen ethyl phosphonate (IHEP-H) ${ }^{-}, 13$ : cyclohexyl methyl phosphonic acid (CHMPA-H) ${ }^{-}, 14$ : pinacolyl methyl phosphonic acid (PMPA-H) ${ }^{-}$. Notice that the mobility spectrum alone yielded CWA degradation products that have similar mobilities, such as PMPA and CHMPA. This made it difficult to determine significant resolution of these two ions from the complete mixture by ion mobility alone. Further examination of Figure 1 also established that the mass spectrum alone could not resolve all of the CWA degradation products. This was due to ions (IMPA-H) ${ }^{-}$and (EHEP$\mathrm{H})^{-}$having the same mass flight times. However, the combination of ion mobility and mass spectrometry in tandem, i.e., IM(tof)MS, provided a powerful 2-D mode of acquisition for the identification and quantification of all aqueous CWA degradation products at once, making it possible to clearly determine each of the parent ions, respective fragments, signal intensity, mobility drift, and mass flight times produced from within a single experimental run.

Tabulated values for each of the CWA degradation products analyzed in this study are shown in Table 1. Here, the ions $(\mathrm{M}-\mathrm{N})^{-}$, masses, drift times, reduced mobility constants $\left(K_{o}\right)$, and signal intensities are reported. All six G-series CWA degradation products produced both proton-loss parent ions, $(\mathrm{M}-\mathrm{H})^{-}$and functional-group loss collision induced dissociation (CID) fragments upon transition of the IM(tof)MS pressure interface. More specifically, when fragmentation occurs between the pressure interface (1.2 torr) and the vacuum of the TOFMS $\left(4 \times 10^{-6}\right.$ torr $)$ the CID fragments observed possess the same mobility drift times as their respective parent ions. For example, PMPA produced both a parent (PMPA-H) ${ }^{-}$and a methyl phosphonic acid CID fragment (PMPA- $\left.\mathrm{H}-\mathrm{C}_{6} \mathrm{H}_{12}\right)^{-}$ion with different mass flight times but identical mobility drift times. The fragment ion resulted from a collision induced rearrangement loss of the $\mathrm{C}_{6}$ alkene. Likewise, IHEP produced both a parent (IHEP-H) ${ }^{-}$and a ethyl phosphonic acid CID fragment (PMPA- $\left.-\mathrm{H}_{3} \mathrm{H}_{6}\right)^{-}$ which only differed by their respective mass flight times. This trend was observed for all of the phosphonic acids; in each case CID of the $(\mathrm{M}-\mathrm{H})^{-}$parent ion yielded fragment ions with losses of alkenes from the alkoxy groups due to CID rearrangements. As a side note, CWA-chloride adducts were not observed even for cases using elevated concentrations of CWA degradation products. The resulting $K_{o}$ values obtained for the examined CWA degradation products are, to our knowledge, the first ever published results for these compounds in the negative ion mode. Moreover, the comparison of these experimentally determined $K_{o}$ values to some of those found in literature for positive 
Table 1. CWA degradation products identified by this study; ions, masses, drift times, $K_{o}$ values, and signal intensities

\begin{tabular}{|c|c|c|c|c|c|}
\hline & lons $(M+N)^{a}$ & Mass (Da) & Drift Time $(\mu \mathrm{s})$ & $K_{o}^{\mathrm{b}}\left(\text { Lit } K_{o}\right)^{\mathrm{c}}$ & Intensity ${ }^{\mathrm{d}}(\mathrm{RSD})^{\mathrm{e}}$ \\
\hline \multirow[t]{2}{*}{ EMPA } & $(\mathrm{M}-\mathrm{H})^{-}$ & 123.08 & $1.157 \times 10^{4}$ & $1.79(1.75,1.78)$ & $252.6(1.46)$ \\
\hline & $\left(\mathrm{M}-\mathrm{H}-\mathrm{C}_{2} \mathrm{H}_{4}\right)^{-}$ & 95.02 & $N / A^{a}$ & $N / A^{a}$ & $224.3(1.58)$ \\
\hline \multirow[t]{2}{*}{ IMPA } & $(\mathrm{M}-\mathrm{H})^{-}$ & 137.10 & $1.226 \times 10^{4}$ & $1.70(1.72)$ & $295.2(1.35)$ \\
\hline & $\left(\mathrm{M}-\mathrm{H}-\mathrm{C}_{3} \mathrm{H}_{6}\right)^{-}$ & 95.02 & $N / A^{a}$ & $N / A^{a}$ & $186.3(1.58)$ \\
\hline \multirow[t]{2}{*}{ EHEP } & $(\mathrm{M}-\mathrm{H})^{-}$ & 137.10 & $1.206 \times 10^{4}$ & 1.73 & $267.2(1.35)$ \\
\hline & $\left(\mathrm{M}-\mathrm{H}-\mathrm{C}_{2} \mathrm{H}_{4}\right)^{-}$ & 109.03 & $N / A^{a}$ & $N / A^{a}$ & $217.8(1.38)$ \\
\hline \multirow[t]{2}{*}{ IHEP } & $(\mathrm{M}-\mathrm{H})^{-}$ & 151.13 & $1.292 \times 10^{4}$ & 1.63 & $483.3(1.68)$ \\
\hline & $\left(\mathrm{M}-\mathrm{H}-\mathrm{C}_{3} \mathrm{H}_{6}\right)^{-}$ & 109.03 & $N / A^{a}$ & $N / A^{a}$ & $328.8(1.38)$ \\
\hline \multirow[t]{2}{*}{ CHMPA } & $(\mathrm{M}-\mathrm{H})^{-}$ & 177.17 & $1.426 \times 10^{4}$ & 1.46 & $363.3(1.63)$ \\
\hline & $\left(\mathrm{M}-\mathrm{H}-\mathrm{C}_{6} \mathrm{H}_{10}\right)^{-}$ & 95.02 & $N / A^{a}$ & $N / A^{a}$ & $41.3(1.58)^{f}$ \\
\hline \multirow[t]{2}{*}{ PMPA } & $(\mathrm{M}-\mathrm{H})^{-}$ & 179.18 & $1.426 \times 10^{4}$ & 1.46 & $323.5(1.21)$ \\
\hline & $\left(\mathrm{M}-\mathrm{H}-\mathrm{C}_{6} \mathrm{H}_{12}\right)^{-}$ & 95.02 & $N / A^{a}$ & $N / A^{a}$ & $41.3(1.58)^{f}$ \\
\hline
\end{tabular}

amobility information not applicable for CID fragment ions.

${ }^{b} K_{o}$ Values are in $\mathrm{cm}^{2} \mathrm{~V}^{-1} \mathrm{~s}^{-1}$.

cpositive mode literature $K_{o}$ values 20 .

dsignal intensity.

e percent relative standard deviation (RSD) for three experimental runs.

${ }^{f}$ combined signal intensity from CHMPA and PMPA fragmentation.

mode [20], as shown in Table 1, helps to not only further validate the use of the IM(tof)MS instrument for the accurate identification of CWA degradation products but also to provide an insight as to how negatively charged ions behave as they move through the APIMS drift space. For example, both EMPA and IMPA exhibited a close similarity between their positive and negative mode $K_{o}$ values, even though they were run on different occasions. Lastly, as might be expected, most CWA degradation products exhibited relatively similar signal intensities, mainly due to what appears to be common efficiency of proton extraction from hydroxyl $\left(\mathrm{OH}^{-}\right)$functional groups. It should be noted that IHEP showed the highest signal intensity followed by CHMPA and PMPA, respectively.

\section{Conclusions}

The main advantage of IM(tof)MS technology over IMS or MS technology alone is its ability to provide rapid 2-D data acquisition spectra with the capacity to electronically couple and decouple CID to generate ion fragmentation patterns. This in turn facilitates the identification of mobility selected parent ions, permitting rapid compound identification and significantly reducing the number of false positive responses [21]. Here, the employment of the IM(tof)MS in negative ion monitoring mode has shown the detection capacity (accuracy, precision, and robustness) to be used for a complex aqueous phase mixture of CWA degradation products. Using this approach, it was possible to clearly determine each of the parent ions, respective CID fragments, signal intensity, mobility drift, and mass flight times produced from within a single experimental run. The significance of this study now opens the door to IM(tof)MS technology as a means to conclusively detect Schedule 1, 2, and 3 toxic chemicals or their precursors as stated in the CWC verification and related analysis annex [25] in either positive ion monitoring mode $[20-22,26]$ or negative ion monitoring mode, thereby increasing the reliability of identification and decreasing the potential for false positive responses. While this study was limited to the detection of a single class of G-series aqueous phase CWA degradation products in negative IM(tof)MS ion monitoring mode, the analytical principles demonstrated in this study are expected to be applicable to a wide range of compounds such as inorganic anions, explosives, sugars, and other analytes which can produce negative gas-phase ions.

\section{Acknowledgments}

The authors acknowledge Ionwerks of Houston Texas and the Edgewood Chemical Biological Center, Aberdeen Proving Grounds, MD, for their continued scientific correspondence. This work was supported in part by Geo-Centers Incorporated (grants 40853CMGC3173 and 42090SM).

\section{References}

1. (a) Burgen, A.S. V.; Hobbiger, F. The Inhibition of Cholinesterases by Alkyl Phosphates and Alkylphenol Phosphate. Br. J. Pharmacol. Chemother. 1951, 6, 593-605; (b) Grob, D.; Harvey, A. M. The Effects and Treatment of Nerve Gas Poisoning. Am. J. Med. 1953, 14, 52-63; (c) Grob, D. The Manifestations and Treatment of Poisoning Due to Nerve Gas and Other Organic Phosphate Anticholinesterase Compounds. Arch. Int. Med. 1956, 98, 221239; (d) Grob, D.; Harvey, J. C. Effects in Man of the Anticholinesterase Compound Sarin. I. Clin. Invest. 1958, 37, 350-368; (e) Koelle, G. B.; Compton, J. A. F. Military Chemical and Biological Agents: Chemical and Toxicological Properties; Telford Press: Caldwell, NJ, 1987; (f) Ballantyne, B.; Marrs, T. C. Pharmacology and Toxicology of Organophosphates; Butterworth-Heinemann: Oxford, 1992; pp 35-39.

2. (a) Fox, M.; Scott, D. The Genetic Toxicology of Nitrogen and Sulfur Mustard. Mutat. Res. 1980, 75, 131-168; (b) Somani, S. M.; Babu, S. R. Toxicodynamics of Sulfur Mustard. Int. J. Clin. Pharm. Therap. Toxicol. 1989, 9, 419-435; (c) Papinmeister," B., Feister," A. J., Robinson,, S. I., Ford,, R. D. Medical Defense Against Mustard Gas: Toxic Mechanisms and Pharmacological Implications; CRC Press, Boca Raton, FL, 1991.

3. (a) Gosselin, R. E.; Smith, R. P.; Hodge, H. C. Clinical Toxicology of Commercial Products, 5th ed.; Williams and Wilkins: Baltimore, 1984; (b) Hathaway, G. J., Proctor, N. H., Hughes, J. P., Fischman,, M. L. Proctor and Hughes' Chemical Hazards of the Workplace, 3rd ed.; Van Nostrand Reinhold: NewYork, 1991.

4. (a) Berghoff, R. S. The More Common Gases: Their Effect on the Respiratory Tract. Observation on Two Thousand Cases. Arch. Int. Med. 1919, 24, 678-684. (b) Gilchrist, H. L.; Matz, P. B. The Use of Mustard Gas with Report Cases. Med. Bull. Veterans Admin. 1933, 9, 339-390. (c) Cucinell, S. A. Review of the Toxicity of Long-Term Phosgene Exposure. Arch. Environ. Health 1974, 28, 272-275. 
5. Kingery, A. F.; Allen, H. E. The Environmental Fate of Organophosphate Nerve Agents: A Review. Toxicol. Environ. Chem. 1995, 47, 155-184.

6. (a) Vasil'ev, I. A.; Shvyryaev, B. V.; Liberman, B. M.; Sheluchenko, B. V.; Petrunin, V. A.; Gorskii, V. G. Kinetics and Mechanism of Sarin Reaction with Monoethanolamine and Mathematical Modeling of a Reactor Unit for Detoxification. Mendeleev Chem. J. 1995, 39(4), 5-10; (b) Yang, Y. C.; Bake, J. A.; Ward, J. R. Decontamination of Chemical Warfare Agents. Chem. Rev. 1992, 92, 1729-1743; (c) Yang, Y. C. Chemical Detoxification of Nerve Agent VX. Acc. Chem. Res. 1999, 32, 109-115; (d) Wagner, G. W.; Yang, Y. C. Rapid Nucleophilic/Oxidative Decontamination of Chemical Warfare Agents. Ind. Eng. Chem. Res. 2002, 41(8), 1925-1928.

7. Cheicante, R. L.; Stuff, J. R.; Durst, H. D. Separation of Sulfur Containing Chemical Warfare Related Compounds in Aqueous Samples by Micellar Electrokinetic Chromatography. J. Cap. Elec. 1995, 4, 157-163.

8. (a) Larsson, L. The Alkaline Hydrolysis of Two Sarin Analogs and of Tabun. Acta Chim. Scand. 1958, 12, 783-785; (b) Gustafson, R. L.; Martell, A. E. A Kinetic Study of the Copper (II) Chelate-Catalyzed Hydrolysis of Isopropyl Mehtylphosphonofluoridate. J. Am. Chem. Soc. 1962, 84, 23092316; (c) Epstein, J. Rate of Decomposition of GB (Isopropyl Methylphosphonafluoridate) in Seawater. Science 1970, 170, 1936-1938; (d) Ellin, R. I.; Groff, W. A.; Kaminskis, A. The Stability of Sarin and Soman in Dilute Aqueous Solutions and the Catalytic Effect of Acetate Ion. J. Environ. Sci. Health B 1981, B16(6), 713-717; (e) Desire, B.; Saint-Andre, S. Interaction of Soman with $\beta$-Cyclodextrin. Fundam. Appl. Toxicol. 1986, 7(4), 646-657; (f) Hammond, P. S.; Forster, J. S. A Polymeric Amine-Copper (II) Complex as Catalyst for the Hydrolysis of 1,2,2-Trimethylpropyl Methylphosphonofluoridate (Soman) and bis(1 -Methylethyl)Phosphonofluoridate (DFP). J. Appl. Polym. Sci. 1991, 43(10), 1925-1931.

9. (a) Ketelaar, J. A. A.; Gersmann, H. R.; Beck, M. M. Metal-Catalyzed Hydrolysis of Thiophosphoric Esters. Nature 1956, 177, 392-393; (b) Epstein, J * Callahan, J. J. Bauer, V. E. Kinetics and Mechanisms of Hydrolysis of Phosphonothiolates in Dilute Aqueous Solution. Phosphorus Relat. Group V Elem. 1974, 4, 157-163; (c) Yang, Y. C.; Szafraniec, L. L.; Beaudry, W. T.; Bunton, C. A. Perhydrolysis of Nerve Agent VX, J. Org. Chem 1993, 58,6964-6965.

10. (a) Bartlett, P. D; Swain, C. G. Kinetics of Hydrolysis and Displacement Reactions of $\beta, \beta^{\prime}$-Dichlorodiethyl Sulfide (Mustard Gas) and of $\beta$-Chloro- $\beta$-Hydroxydiethyl Sulfide (Mustard Chlorohydrin). J. Am. Chem. Soc. 1949, 71, 1406-1415; (b) Waters, W. A.; Williams, J. H. Hydrolyses and Derivatives of Some Vesicant Arsenicals. J. Chem. Soc. 1950, Abstr. 18-22; (c) Yang, Y. C.; Szfraniec, L. L.; Beaudry, W. T.; Ward, R. J. Kinetics and Mechanism of Hydrolysis of 2-Chloroethyl Sulfides. J. Org. Chem. 1988, 53(14), 3293-3297; (d) Meylan, W. M.; Howard, P. H. Atom/Fragment Contribution Method for Estimating Octanol-Water Partition Coefficients. J. Pharm. Sci. 1995, 84(1), 83-92.

11. (a) Douglas, D. E.; Winkler, C. A. Preparation, Purification, Physical Properties, and Hydrolysis of Cyanogen Chloride. Can. J. Res. 1947, 25B, 186-381; (b) Francke, S. Manual of Military Chemistry, Vol. I. Chemistry of Chemical Warfare Agents; Deutscher Militirverlag: Berlin, 1967; Translated from German by U.S. Department of Commerce, National Bureau of Standards, Institute for Applied Technology, NTIS no. AD-849-866; (c) Khorkin, A. A.; Temkin, O. N.; Flid, R. M. Kinetics of Acidic Hydrolysis of Prussic Acid. Zhurnal. Fizicheskoi. Khimii. 1967, 41(2), 299-302.

12. (a) Leitner, C. Chemical Warfare and the Red Cross Disintoxication of Water Contaminated with Gases. Chim. Et. Indust. 1930, 23, 381-386; (b) Dardan, D.; Popa, S. Influence of Alkalinity on the Adsorbing Poser of Activated Carbon for Warfare Gases: Phosgene, Chlorine, Chloropicrin, and Hydrocyanic Acid. Chim. Et. Indust. 1940, 44, 206; (c) Potter, H. H. The Effects of War Gases on Water Supplies: Decontamination. J. New Eng. W. W. Assc. 1943, 57, 137-162.

13. (a) Roach, M. C.; Unger, L. W.; Zare, R. N.; Reimer, L. M.; Pumpliano, J. W.; Frost, J. W. Fluorescence Detection of Alkylphosphonic Acids Using p-(9-Anthroyloxy)Phenacyl Bromide. Anal. Chem. 1987, 59, 10561059; (b) Purdon, J. G.; Pagotto, J. G.; Miller. R. K. Preparation, Stability, and Quantitative Analysis by Gas Chromatography and Gas Chromatography-Electron Impact Mass Spectrometry of Tert-Butyldimethylsilyl Derivatives of Some Alkylphophonic and Alkyl Methylphosphonic Acids. J. Chromatogr. 1989, 475, 261

14. (a) Toernes, J. A.; Johnson, B. A. Gas Chromatographic Determination of Methylphosphonic Acids with Trimethylphenylammonium Hydroxide. J. Chromatogr. 1989, 467, 129-138; (b) Kientz, C. E. Chromatography and Mass Spectrometry of Chemical Warfare Agents, Toxins, and Related Compounds: State of the Art and Future Prospects. J. Chromatogr. 1998, 814(1), 1-23.

15. (a) Kingery, A. F.; Allen, H. E. Ion Chromatographic Separation of Closely Related Nerve Agent Degradation Products Using and Organic Modifier to Provide Selectivity. Anal. Chem. 1994, 66(1), 155-159; (b) Bossle, P. C.; Reutter, D. J.; Sarver, E. W. Analysis for Alkyl Methylphosphonic Acids in Aqueous Matrixes by Ion-Pair Reversed-Phase Ion Chromatography. J. Chromatogr. 1987, 407, 399-404.

16. Berkout, V. D.; Cotter R. J.; Segers, D. P. Miniaturized, E.I./Q/oa TOF Mass Spectrometer. Am. Soc. Mass Spectrom. 2001, 12, 641-647.

17. (a) Asbury, R. G.; Wu, C.; Siems, W. F.; Hill, H. H. Separation and Identification of Some Chemical Warfare Degradation Products Using Electro-Spray High Resolution Ion Mobility Spectrometry with Mass Selected Detection. Anal. Chem. 2000, 404, 273-283; (b) Tabrizchi, M.; Khayamian, T.; Taj, N. Design and Optimization of a Corona Discharge Ionization Source for Ion Mobility Spectrometry. Rev. Sci. Instrum. 2000, 71, 2321-2328.
18. (a) Wils, E. R. J.; Hulst, A. G. Determination of Organophosphorus Acids by Thermospray Liquid Chromatography-Mass Spectrometry. J. Chromatogr. 1988, 454, 261-272; (b) Kostianen, R.; Bruins, A. P.; Hakkinen, V. M. A. Identification of Degradation Products of Some Chemical Warfare Agents by Capillary Electrophoresis-Ionspray Mass Spectrometry. J. Chromatogr. 1993, 634, 113-118; (c) Borrett, V. T.; Mathews, R. J.; Colton, R.; Traeger, J. C. Verification of the United Nations Chemical Weapons Convention: The Application of Electrospray Mass Spectrometry. Rapid Comm. Mass Spectrom. 1996, 10, 114;

(d) Black, R. M.; Read, R. W. Application of Liquid ChromatographyAtmospheric Pressure Chemical Ionization Mass Spectrometry and Tandem Mass Spectrometry to the Analysis and Identification of Degradation Products of Chemical Warfare Agents. J. Chromatogr. 1997, 759, 79-92; (e) D'Agostino, P. A.; Chenier, C. L.; Hancock, J. R. Packed Capillary Liquid Chromatography-Electrospray Mass Spectrometry of Snow Contaminated with Sarin. J. Chromatogr. A 2002, 950, 149-156; (f) D'Agostino, P. A.; Hancock, J. R.; Provost, L. R. Determination of Sarin, Soman, and Their Hydrolysis Products in Soil by Packed Capillary Liquid Chromatography-Electrospray Mass Spectrometry. J. Chromatogr. A. 2001, 912, 291-299; (g) Read, R. W.; Black, R. M. Rapid Screening Procedures for the Hydrolysis Products of Chemical Warfare Agents Using Positive and Negative Ion Liquid Chromatography-Mass Spectrometry with Atmospheric Pressure Chemical Ionization. J. Chromatogr. A 1999, 862, 169-177. (h) D'Agostino, P. A.; Hancock, J. R.; Provost, L. R. Packed Capillary Liquid Chromatography-Electrospray Mass Spectrometry Analysis of Organophosphorus Chemical Warfare Agents. J. Chromatogr. A 1999, 840, 289-294; (i) Black, R. M.; Read, R. W. Analysis of Degradation Products of Organophosphorus Chemical Warfare Agents and Related Compounds by Liquid ChromatographyMass Spectrometry Using Electrospray and Atmospheric Pressure Chemical Ionization. I. Chromatogr. A 1998, 794, 233-244.

19. (a) Noami, M.; Kataoka, M.; Seto, Y. Improved tert-Butyldimethylsilylation Gas Chromatographic/Mass Spectrometric Detection of Nerve Gas Hydrolysis Products from Soils by Pretreatment of Aqueous Alkaline Extraction and Strong Anion-Exchange Solid-Phase Extraction. Anal. Chem. 2002, 74, 4709-4715; (b) Driskell, W. I.; Shih, M.; Needham, L. L.; Barr D. B. Quantitation of Organophosphorus Nerve Agent Metabolites in Human Urine Using Isotope Dilution Gas Chromatography-Tandem Mass Spectrometry. I. Anal. Toxicol. 2002, 26, 6-10; (c) Schneider, J. F.; Boparai, A. S.; Reed, L. L. Screening for Sarin in Air and Water by Solid-Phase Microextraction-Gas Chromatography-Mass Spectrometry. J. Chromatogr. Sci. 2001, 39, 420-424; (d) Brickhouse, M. D.; Creasy, W. R.; Williams, B. R.; Morrissey, K. M.; O'Connor, R. J.; Durst, H. D. Multiple-Technique Analytical Characterization of a Mixture Containing Chemical-Weapons Simulant from a Munition. J. Chromatogr. A 2000, 883, 185-198; (e) Bartram, P. W.; Brickhouse, M. D.; Connell, T. R.; Creasy, W. R.; Henderson, V. D.; Hovanec, J. W.; Morrissey, K. M.; Stuff, J. R.; Wagner, G. W.; Williams, B. R. NMR, LC/MS, GC-IRD/MS, and GC-AED/MS Analysis of the Reactions of GD and VX with Ozone. Proceedings of the ERDEC Conference; Aberdeen Proving Grounds, November, 1999, pp 691-697.

20. Steiner, W. E.; Clowers, B. H.; Matz, L. M.; Siems, W. F.; Hill, H. H. Rapid Screening of Aqueous Chemical Warfare Agent Degradation Products: Ambient Pressure Ion Mobility Mass Spectrometry (IMMS). Anal. Chem. 2002, 74, 4343-4352.

21. Steiner, W. E.; Haigh, P. B.; Clowers, B. H.; Hill, H. H. Secondary Ionization of Chemical Warfare Agent Simulants Using Atmospheric Pressure Ion Mobility Time-of-Flight Mass Spectrometry [IM(tof)MS]. Anal. Chem. 2003, 75, 6068-6078.

22. Steiner, W. E.; Klopsch, S. J.; English, W. A.; Hill, H. H., Jr. Detection of a Chemical Warfare Agent Simulant in Various Aerosol Matrices by Ion Mobility Time-of-Flight Mass Spectrometry [IM(tof)MS]. Anal. Chem. 2005, 77(15), 4792-4799.

23. (a) Wu, C.; Siems, W. F.; Asbury, G. R.; Hill, H. H., Jr. Electrospray Ionization High-Resolution Ion Mobility Spectrometry-Mass Spectrometry. Anal. Chem. 1998, 70, 4929-4938; (b) Dugourd, P. H.; Hudgins, R. R.; Clemmer, D. E.; Jarrold, M. F. High-Resolution Ion Mobility Measurements. Rev. Sci. Instrum. 1997, 68, 1122-1129.

24. (a) Eiceman, G. A.; Karpas, Z. Ion Mobility Spectrometry, 2nd ed.; CRC Press: Boca Ration, FL, 2005; (b) Guevremont, R. High-Field Asymmetric Waveform Ion Mobility Spectrometry: A New Tool for Mass Spectrometry. J. Chromatogr. A 2004, 1058(1/2), 3-19.

25. Chemical Weapons Convention (CWC) bans the development, production, acquisition, stockpiling, and use of chemical weapons and on their destruction. Washington D.C. United States Bureau of Arms Control and Disarmament Agency, Entered into force April 29, 1997.

26. (a) Steiner, W. E.; Clowers, B. H.; Fuhrer, K.; Gonin, M.; Matz, L. M.; Siems, W. F.; Schultz, A. J.; Hill, H. H. Electrospray Ionization With Ambient Pressure Ion Mobility Separation And Mass Analysis By Orthogonal Time-of-Flight Mass Spectrometry, Rapid Commununication in Mass Spectrometry 2001, 15 (23), 2221-2226. (b) Shumate, C. B.; Hill, H. H., Coronaspray Nebulization and Ionization of Liquid Samples for Ion Mobility Spectrometry, Anal. Chem., 1989, 61, 601-606. (c) St. Louis, R. H.; Hill, H. H., Jr. Ion Mobility Spectrometry in Analytical Chemistry, Crit. Rev. Anal. Chem., 1990, 21, 321-355.

27. (a) Ionwerks 3-D Software, Ionwerks Inc, Houston TX, 2004.

28. (a) Transform V3.4, Fortner Software LLC, Serling VA, 1998. Research Systems IDL virtual machine 6.0 Software, Research Systems Inc., Boulder CO, 2004. 